ISSN: 2354 - 1431

http://tckh.daihoctantrao.edu.vn/

\title{
Định kiến xã hội - một vỉa hiện thực mới trong tiểu thuyết và truyện ngắn của Nam Cao trước Cách mạng
}

\author{
Nguyễn Văn Tùng ${ }^{a}$ \\ ${ }^{a}$ Nhà xuất bản Giáo dục Việt Nam
}

\section{Article info}

Recieved:

12/72017

Accepted:

03/8/2017

Keywords:

Social prejudice;Origin;

State;Scorn;Pettiness,

Selfish;Ignorant;

Progressive;

People's intellectual.

\begin{abstract}
The research article focuses on the question of social prejudice in the novels and short stories of Nam Cao before the Revolution. This survey clarifies the position of writer Nam Cao in the trend of literary realism in particular and contributes about the artistic ideas of Nam Cao to modern Vietnamese literature.
\end{abstract}

The author uses the method of documentary research, methods of systematization, generalizations besides some research skills such as analysis, demonstration, comparison...

Since then, the research article has clarified the manifestation of the problem of social prejudice through the world of iconography, the environment, the cause of social prejudice, the way of explaining social prejudice and some solutions of the writer.
Định kiến xã hội chính là cách nhìn nhận cứng nhắc, bảo thủ về bản chất của những con người, loại người, tầng lớp người cụ thể trong đời sống một cộng đồng. Ân tượng không tốt về một người, một loại người tại một thời điểm đã duy trì lâu dài trong ý thức của các thành viên cộng đồng. Định kiến cũng là sự phát huy thái quá của dư luận xã hội.

Định kiến xã hội đã tồn tại lâu trong đời sống. Song Nam Cao là nhà văn đầu tiên đặt vấn đề này một cách hệ thống qua các hình tượng nghệ thuật của mình. Tác giả chỉ ra nhiều phương diện của định kiến xã hội. Ở đây chúng tôi sẽ tập trung làm rõ các phương diện: Định kiến về nguồn gốc xuất thân, về quá khứ bất hảo - Định kiến về ngôi thứ trong làng xã - Định kiến về đạo đức, phẩm hạnh của người phụ nữ. Qua các phương diện này để tiếp tục tìm hiểu cơ sở - môi trường nảy sinh, tồn tại của định kiến xã hội; nguyên nhân dẫn đến định kiến xã hội, diễn biến của định kiến xã hội và hậu quả của định kiến xã hội.

1. Trước hết, Nam Cao đề cập nhiều đến định kiến về nguồn gốc xuất thân, về quá khứ bất hảo. Từ lâu con người đã có tư tưởng đề cao dòng giống xuất thân. Những người xuất thân từ một gia đình quý phái, từ một dòng họ nổi danh thường được coi trọng. Nhưng từ đó, nhiều người đi đến một thái cực đối ngược là coi thường, khinh miệt, thậm chí tẩy chay những người có nguồn gốc xuất thân tầm thường, không rõ ràng. Tư tưởng ấy đã ám ảnh họ trong cách đánh giá, nhìn nhận con người. Đây là một nội dung mà Nam Cao khai thác và gửi gắm nhiều tư tưởng qua các hình tượng như Chí Phèo (Chí Phèo), Trạch Văn Đoành (Đôi móng giò), Đức (Nửa đêm)...

Chí Phèo bị coi thường, bị khinh miệt trước hết vì hắn là một "thằng không cha không mẹ". Không có một tổ ấm gia đình, nên từ ngày người nuôi hắn chết đi, hắn trở thành một kẻ bơ vơ, đi ở cho hết nhà này đến nhà khác. Đó cũng là lí do dẫn hắn đến với gia đình nhà Bá kiến làm canh điền, để rồi Chí Phèo phải từ bỏ cuộc đời lương thiện, bước vào con đường tù tội, du côn.

Trạch Văn Đoành (Đôi móng giò) có nhiều hành động phản ứng lại những vị có chức sắc trong làng cũng chỉ vì hắn bị họ khinh thường. Cho dù hắn đã thành kẻ có tiền, được người làng gọi là ông, nhưng hắn vẫn không được những ông kì mục trong làng tôn trọng. Định kiến về nguồn gốc xuất thân thấp hèn của Trạch Văn Đoành không dễ dàng được quên đi. Những người cho rằng mình có nguồn gốc đàng hoàng không thể chấp nhận được một "thằng bạch đinh, con một lão đi câu chết mất xác dưới sông, bỏ làng đi chán đi chê, rồi đột nhiên trở về nhảy tót lên bao lan ngồi làm một ông kì mục".

Số phận của Đức (Nửa đêm) phần lớn do định kiến xã hội quyết định. Dân làng Vũ Đại không thể coi Đức là con người bình thường. Ngay từ khi Đức còn là một cậu bé phải đi xin sữa, người ta đã tỏ ra ghê tởm hắn. Người 
ta bị ám ảnh bởi ý nghĩ Đức mang trong mình dòng máu của một kẻ giết người, tội lỗi. Những người phụ nữ vú đầy căng sữa nhưng từ chối không cho, vài người vì nể hay thương hại mà cho sữa sau đó thì vội vàng lau, rửa vú thật kĩ càng, sạch sẽ. Nhưng đó là một định kiến hoàn toàn sai lầm và đáng phê phán. Bởi khác với Trương Rự, Đức hoàn toàn hiền lành, hiền lành đến ngờ nghệch. Vậy mà Đức phải chịu một số phận hết sức cay đắng. Hắn bị người làng cô lập và trở thành một kẻ lầm lũi. Định kiến đã cướp đi của Đức quyền được giao lưu với cộng đồng, quyền được yêu, được mưu cầu hạnh phúc. Đến một người côn gái thô mộc, xấu xí, thấp hèn như Nhi mà Đức cũng không thể lấy làm vợ. Qua lời Nhi nói với Đức có thể thấy rất rõ cách nghĩ của mọi người đối với Đức: "Anh Đức ạ! Tôi mà lấy anh cũng chỉ vì mến cái nết anh hiền, chứ người khác mà bố mẹ như bố mẹ anh thì các vàng tôi cũng chịu. Anh đừng giận: tôi dám chắc ế thì thôi chứ chẳng ai đâm đầu vào lấy con một thằng ăn cướp, giết người, một đứa chồng vừa chết chưa ráo mồ, con vừa sinh còn đỏ hon hỏn đã vội theo trai...". Và cũng chính định kiến của người làng Vũ Đại đã đẩy Đức khỏi làng để khi trở về hắn thành một kẻ điên điên, khùng khùng.

Qua số phận nhân vật Đức có thể thấy rất rõ sức mạnh vô hình của định kiến xã hội. Nó có thể làm thay đổi cuộc đời của những con người không may rơi vào những tình thế, hoàn cảnh éo le.

Một mặt khác của định kiến xã hội mà Nam Cao cũng đặt ra qua các hình tượng của mình đó là thái độ của cộng đồng đối với quá khứ bất hảo của một cá nhân nào đó. Với sự hạn chế trong cách nhìn nhận con người, nhiều người không thừa nhận sự phục thiện. Họ thẳng thừng bác bỏ nguyện vọng tha thiết được quay trở về với cuộc sống lương thiện. Bằng trái tim nhân hậu sâu sắc và một trí tuệ, một quan điểm sáng suốt, Nam Cao đã nhìn thấu tâm can của những con người bị cộng đồng ruồng bỏ. Ông hiểu họ và gián tiếp cho rằng những con người ấy rất có thể sẽ trở lại làm người tốt nếu như được cộng đồng tha thứ. Những trang văn miêu tả tâm trạng của Chí Phèo sau khi gặp thị Nở bằng những hành động chăm sóc rất gần gũi, thân thương đã đánh thức con người lương thiện trong Chí Phèo. Hắn thiết tha muốn trở về với cuộc đời: "Trời ơi! Hắn thèm lương thiện, hắn muốn làm hoà với mọi người biết bao? Thị Nở sẽ mở đường cho hắn. Thị có thể sống yên ổn với hắn thì sao người khác lại không thể được. Họ sẽ thấy rằng hắn cũng không thể làm hại được ai. Họ sẽ lại nhận hắn vào cái xã hội bằng phẳng, thân thiện, của những người lương thiện". Vậy nhưng người làng Vũ Đại không thể tha thứ cho hắn bởi vì hắn đã là một thằng lưu manh. Họ ngăn bước Chí Phèo đến làm hoà với họ. Với họ, hắn không thể quay lại làm người, bởi vì hắn đã làm một con quỷ dữ. Họ phũ phàng chặt phăng chiếc cầu nối giữa Chí Phèo với cuộc đời, đó là Thị Nở. Sự đối xử đó của cộng đồng Vũ Đại đã nhanh chóng đẩy số phận Chí Phèo đi tới hồi kết.

2. Thứ hai, Nam Cao đề cập đến định kiến về ngôi thứ trong làng xã. Đây cũng là một nội dung nổi bật của định kiến xã hội trong tác phẩm của Nam Cao. Bằng một số hình tượng tiêu biểu, Nam Cao phản ánh chân thực một hiện thực xã hội tồn tại khá phổ biến trong các cộng đồng làng xã. Giá trị của con người được đo bằng các ngôi thứ cụ thể trong cái trật tự xã hội ấy. Những người ở địa vị thấp bị khinh miệt, thậm chí thường xuyên bị một số thành viên khác ở địa vị cao hơn trong cộng đồng lăng mạ. Cu Lộ trong Tu cách mõ là một nạn nhân tiêu biểu của định kiến này.

Xem xét quá trình vận động của nhân cách cu Lộ, có thể thấy rằng viẹc cu Lộ chấp nhận địa vị một thằng mõ bên cạnh lí do hắn nghèo khổ không thể không kể đến sự đưa đẩy của các thành viên trong họ đạo Lưu An. Bởi thế nhân vật cu Lộ còn có ý nghĩa phê phán sự vô lí của thái độ coi thường những con người ở địa vị thấp kém trong cộng đồng xã hội. Nhà văn thể hiện sinh động một tư tưởng nhân sinh, rằng việc người ta khinh miệt kẻ khác thấp hơn mình để đề cao mình là một điều sai lầm. Thực chất thái độ ứng xử ấy không thể làm tăng giá trị của một ai, mà điều chắc chắn là sẽ giết chết những nhân cách, làm cho cuộc sống của xã hội trở nên xấu xa hơn.

Thái độ phê phán định kiến về ngôi thứ trong làng xã còn được thể hiện khá cụ thể ở nhân vật Bịch trong $M u a$ danh. Hắn đã xót xa mà bỏ ra cả một khoản tiền lớn để mua lấy cái danh "ông hương", nhưng rốt cuộc vẫn là cái danh hão. Bịch vẫn chỉ là một người bị mọi người coi thường, bị "cụ tiên chỉ" sai vặt thôi.

Đằng sau nụ cười chua chát khi xây dựng nhân vật này, Nam Cao còn bộc lộ sự suy ngẫm sâu sắc về một kiểu nô lệ tư tưởng của con người. Định kiến về ngôi thứ trong làng xã quả là đã ăn sâu vào lối sống, cách nghĩ của con người ta, buộc con ngời ta hành động một cách ngoan ngoãn và mù quáng. Vấn đề này sẽ được phân tích kĩ hơn ở sau.

3. Thứ ba, nhà văn dành nhiều trang viết phản ánh định kiến về đạo đức, phẩm hạnh của người phụ nữ. Trong một xã hội mà cái đói, cái dốt nát và sự bất công đầy rẫy thì người phụ nữ khó có thể được coi trọng. Nhiều nhân vật phụ nữ của Nam Cao phải chịu một số phận và ở trong những cảnh ngộ hết sức thương tâm. Họ là những người vợ, người mẹ có trách nhiệm lớn trong các gia đình, nhưng thường bị những ông chồng vũ phu sai khiến, áp đặt sự "cai trị" hết sức khốc liệt. 
Lòng đồng cảm, sự bênh vực của Nam Cao còn được thể hiện ở sự đề cập đến thái độ của xã hội đối với đạo đức, phẩm hạnh của người phụ nữ. Nhà văn không ngần ngại khi nói đến những thói hư, tật xấu của họ. Nhưng một mặt khác, ông đặt vấn đề cần có một cái nhìn bao dung, độ lượng với họ. Đó không phải là một quan điểm ứng xử xuất phát từ một tình thương chung chung mà có cơ sở từ sự phân tích hiện thực xã hội tinh tế và sắc sảo. Tác giả không phủ định một thực tế là rất nhiều người phụ nữ đã phạm những lỗi lầm. Nhưng một mặt khác, bằng các chi tiết và hoàn cảnh nhân vật, nhà văn gián tiếp kêu gọi sự thông cảm ở người đọc.

Trong Chuyện người hàng xóm, nhân vật người phụ nữ là mẹ của Hiền có một số phận vô cùng đáng thương. Người mẹ ấy một mình nuôi con, phiêu bạt đến xóm Bài Thơ thuê nhà trọ, vất vả tìm kế sinh nhai. Trong hoàn cảnh éo le ấy, đối với người phụ nữ, một người đàn ông làm chỗ dựa là hết sức cần thiết. Và chị không thể tránh khỏi một sai lầm là có mang với Cai Minh - một người đàn ông vô trách nhiệm. Vậy là đối với những người ở xóm Bài Thơ, chị là người phụ nữ đổ đốn, chửa hoang một tội lỗi khó lòng tha thứ. Họ đã khiến chị không còn can đảm mà tiếp tục sinh sống nơi xóm nhỏ ây nữa. Đến gần cuối truyện, người phụ nữ này lại xuất hiện trong dáng vẻ vô cùng tiều tuỵ. Và rồi chuyến tàu đã mang chị đi trong nỗi thương cảm tuyệt vọng của người con trai. Thái độ ứng xử của cộng đồng những người thị dân nghèo không chỉ quyết định số phận của chị mà còn thay đổi số phận của Hiền - con trai người phụ nữ ấy.

Trong tiểu thuyết Sống mòn, nhân vật Thứ cũng bộc lộ nhiều suy nghĩ trăn trở về đạo đức, phẩm hạnh của người phụ nữ. Cách đặt vấn đề của Nam Cao ở đây khá rõ ràng. Nhiều đoạn người đọc có cảm giác lời đối thoại hay độc thoại nội tâm của nhân vật cũng chính là của nhà văn. Đó là những suy tư nhiều chiều luôn day dứt tinh thần của nhân vật, phản ánh quá trình thay đổi về nhận thức đối với người phụ nữ.

4. Nam Cao qua những hình tượng đó đã chỉ ra cơ sở môi trường nảy sinh, tồn tại của định kiến xã hội. Nhân vật trong thế giới nghệ thuật Nam Cao thuộc rất nhiều tầng lớp, giai cấp khác nhau trong xã hội. Địa bàn cư trú của họ đương nhiên là phân bố ở khắp nơi, từ thành phố, thị xã đến nông thôn. Xem xét hệ thống các nhân vật tiêu biểu cho vấn đề định kiến xã hội mà Nam Cao đã xây dựng thì phần lớn họ đều thuộc giai cấp nông dân. Và cộng đồng làng xã chính là môi trường chủ yếu làm nảy sinh, tồn tại của định kiến xã hội.

Từ bao đời, hình thức sinh tụ chủ yếu của người Việt là tập hợp lại trong các làng xã, thôn ấp. Các trung tâm thương mại, công nghiệp chiếm một tỉ lệ nhỏ. Đây chính là đặc điểm nổi bật của một nền văn minh nông nghiệp còn ở trình độ lạc hậu. Đặc điểm này chi phối rất mạnh mẽ vào nếp sống, sinh hoạt, nếp nghĩ của các thành viên trong cộng đồng. Trật tự xã hội được duy trì bằng các "lệ làng". Kinh tế xã hội là kinh tế tự cung tự cấp. Sự giao lưu diễn ra rất hạn chế, yếu ớt. Làng xã, thôn ấp là những đơn vị hành chính có tính chất khép kín. Đằng sau luỹ tre làng là những con người rất ít khi thay đổi. Từ thế hệ này đến thế hệ khác, họ quen làm việc, sinh hoạt, tư duy theo những nếp cũ.

Nam Cao vốn sinh ra và lớn lên ở nông thôn, nên ông có vốn sống lớn về những phong tục, tập quán, tác phong của người nông dân. Hơn thế nữa, lại là người có cái nhìn gần gũi đối với nông dân, nên Nam Cao rất hiểu đời sống tinh thần của họ. Nhiều hình tượng nghệ thuật của Nam Cao đã khẳng định những phẩm chất tốt đẹp của người nông dân. Nhà văn trân trọng, ca ngợi họ. Song ông cũng thẳng thắn chỉ ra những khiếm khuyết, những hạn chế của họ. Nam Cao thực sự là một người cầm bút có cái nhìn rất khách quan, khoa học về con người nói chung và về người nông dân nói riêng.

Định kiến chính là một điểm hạn chế của người nông dân mà qua các tác phẩm Nam Cao đã chỉ ra và phê phán. Định kiến là cách nhìn nhận, đánh giá khá phổ biến của người nông dân. Nó thể hiện sự bảo thủ, trì trệ trong tư tưởng của họ. Định kiến cũng thể hiện trình độ văn hoá còn thấp kém của họ. Nó có ảnh hưởng mạnh mẽ và không tốt cho đời sống cộng đồng, nhằm vào một số cá nhân cụ thể và một số loại người cụ thể. Các nhân vật tiêu biểu của vấn đề định kiến xã hội nêu ở trên đều là các nạn nhân của định kiến. Số phận, nhân cách của họ sẽ khác nếu như họ được cộng đồng tôn trọng, đồng cảm...

Trong số các nhân vật là nạn nhân của định kiến xã hội, có hai nhân vật Hiền và mẹ Hiền trong Chuyện nguời hàng xóm không thuộc giai cấp nông dân. Họ là dân nghèo thành thị trong một xóm nhỏ ngoại ô. Qua những chi tiết miêu tả của nhà văn, có thể thấy cuộc sống của những người nơi đây cũng chẳng có gì sáng sủa hơn cuộc sống của những người nông dân. Họ là người tứ xứ đến quần tụ ở xóm nhỏ này. Mỗi người mỗi nghề, mỗi nhà mỗi cảnh. Và ở đó cũng đầy rẫy những chuyện nhỏ nhen, ghen tuông, nhòm ngó. Chính họ buộc mẹ con Hiền phải phiêu dạt đi nơi đất khác. Những cách nhìn nhận đầy định kiến là một thực tế nhức nhối đang tồn tại ở đây. Hiện thực ấy góp phần làm cho cuộc sống của họ thêm u ám, quẩn quanh.

Bởi thế, cơ sở - môi trường tồn tại của định kiến xã hội không chỉ là các cộng đồng làng xã mà còn là cộng 
đồng dân nghèo thành thị. Nói một cách khái quát, định kiến xã hội tồn tại ở những nơi mà cái đói, cái dốt nát đang hoành hành và ngự trị trong đời sống của những con người thấp hèn, nhỏ bé.

Nông dân, dân nghèo thành thị là những tầng lớp, giai cấp dưới đáy xã hội. Bằng việc chỉ ra định kiến xã hội ở những cộng đồng người này, Nam Cao phản ánh chân thực một vỉa hiện thực mới, đó là trực trạng của sự chia rẽ, xâu xé trong nội bộ những người dưới đáy của xã hội. Điều đó làm cho cuộc sống của họ vốn đã hết sức đen tối lại càng thêm ngột ngạt, căng thẳng. Chẳng ở điểm này, nhà văn đã khẳng định cảm quan hiện thực tinh tường và sắc sảo của mình. Hiện thưc này là hiện thực ở chiều sâu. Hiện thực ấy bị chìm khuất bởi biết bao sự kiện hàng ngày, mà chỉ có những nhà văn có năng lực quan sát bởi Nam Cao mới có thể phát hiện được.

5. Nam Cao cũng tìm cách lí giải nguyên nhân dẫn đến vấn đề định kiến xã hội. Tại sao những con người vốn cùng một tầng lớp, một giai cấp lại có thái độ ứng xứ với nhau khắc nghiệt như vậy? Tình thân ái, sự khoan dung độ lượng của những người cùng chung một cộng đồng ở đâu? Tại sao con người đối với con người lại nhiều sự nhỏ nhen, ích kỉ đến thế?

Quả thật, chính Nam Cao là người đã đặt ra vấn đề nhân cách trong quan hệ cộng đồng một cách khá hệ thống. Chỉ nhìn qua một số tên tác phẩm của ông cũng có thể thấy được điều đó: Tu cách mõ, Mua danh, Một bà hào hiệp, Nhỏ nhen, Nhìn nguời ta sung suoóng. Nhân cách của các nhân vật mà Nam Cao đề cập phần lớn có chiều hướng không tốt. Hoặc nếu một nhân cách tốt thì lại bị cuộc đời hắt hủi, chèn ép như trường hợp nhân vật Nhu trong Ở hiền. Ở khía cạnh này, câu nói của Chí Phèo tuyệt đối đúng: "Ai cho tao lương thiện". Dường như tha hoá là một nguy cơ không thể cưỡng lại được trong xã hội ấy. Bên cạnh những nhân cách đã chết, Nam Cao cũng nhẫn mạnh khá nhiều đến sự nhỏ nhen, ích kỉ, bẩn tính... Chỉ tại một con mèo mà vợ nhiếc móc chồng, chồng chửi đánh vợ (Con mèo).

Nhà văn đã lí giải điều đó ra sao? Họ trở nên ích kỉ, lam lũ, vất vả. Vì đói quá, chỉ ích kỉ mới có thể tồn tại được. Vì nghèo quá, chỉ bán nhân cách đi mới đổi được miếng ăn cho vợ, cho con... Nam Cao đã gửi gắm những suy nghĩ của mình về nhân cách của con người qua tâm trạng của nhân vật Thứ. Thứ nghĩ Oanh, nghĩ về sự nhỏ nhen, ích kỉ của con người: "Oanh nhỏ nhen, ích kỉ, tham lam, vì những cái đó, âu cũng là bản tính của loài người. Ít ra đó là những tật chung của loài người, như ta đang hiện thấy quanh ta. Từ lời dạy lòng người, hướng dẫn những hành động của con người ai cũng phải nghĩ đến mình để sống. Chừng nào còn phải giật của người từng miếng ăn thì mới có ăn, chừng nào một số người còn phải dẫm lên đầu những người kia để nhô lên, thì loài người còn phải xấu xa, bỉ ổi, tàn nhẫn và ích kỉ. Người nọ, người kia không đáng cho là ghét. Đáng ghét, đáng nguyền rủa, ấy là cái sống lầm than đã bắt buộc con người ích kỉ, nó đã tạo ra những con người tàn nhẫn và tham lam...".

Định kiến xã hội tồn tại phổ biến trong nội bộ những người lao động nghèo khổ còn bởi vì họ quá dốt nát. Dốt nát đi cùng với sự quẫn bách về vật chất làm cho họ trở nên quẩn quanh hơn. Nhân vật Thứ đã từng thể hiện cái nguyện vọng đẩy lùi được sự dốt nát và đói khát của những người dân lao động cùng khổ: "- Tôi thích làm một việc gì có ảnh hưởng đến xã hội ngay. Dân mình còn đói khổ, ngu dốt quá. Chúng ta phải chống lại nạn đói và nạn dốt". Tư tưởng của Nam Cao trong việc giải quyết vấn đề quan hệ cá nhân với cộng đồng là phải nâng cao dân trí.

6. Tuy nhiên, việc đó sẽ phải làm như thế nào thì nhà văn chưa có câu trả lời thoả đáng. Trong truyện ngắn Nguyện vong, ông đã bộc lệ sự băn khoăn đó. Nhân vật Tá - chồng chị Thanh - đã bỏ một chỗ làm lương hơn bảy chục đồng để trở về với nghề dạy học tư lương ba chục đồng chỉ cốt để thực hiện cho được mục đích cao quý là mở trường lớn, đào tạo nhân tài cho đất nước. Tá hăng hái bộc lộ suy nghĩ: "- ... Mà chẳng riêng gì tôi, những kẻ còn nghĩ đến giống nòi đều nghĩ đến việc đào tạo óc. Vì chỉ có sự học thôi, chỉ có sự học là tạo được con người. Xã hội Việt Nam muốn tiến, quốc dân Việt Nam phải học. Yêu nước, lo đến tương lai của giống nòi, không gì bằng học, khuyến khích việc học, khuếch trương việc học, truyền bá sự học. Gieo hạt giống tốt và óc thiếu niên để đợi lớp người sau, ai yêu nước một cách sáng suốt đều nghĩ như tôi cả". Chỉ tiếc cái "nguyện vọng" tiến bộ ấy chưa thể thực hiện, bởi vì ngay cả đời sống riêng tư của Tá, của gia đình Tá, anh cũng chưa giải quyết được. Vậy nên tác phẩm đã kết thúc bằng một hình ảnh thật xót xa: Tá cười chua chát. Còn nhân vật "Tôi" thì lau nước mắt "đau buồn cho số kiếp Tá, cho số kiếp tôi, số kiếp của tất cả những người có những chân ống sậy mà lại mang những nguyện vọng to tát quá?".

Cho dù vậy, song khi nhà văn đề cập đến sự dốt nát mà ông đã bắt "đúng bệnh" của xã hội. Dốt nát dẫn đến nhiều hậu quả tai hại, trong đó dẫn đến tình trạng định kiến. Bởi vì dốt nát khiến người ta bị nô lệ về mặt tư tưởng. Đây là một khía cạnh mà Nam Cao đặc biệt lưu ý. Sự nô lệ về mặt thân xác đã đáng sợ, song sự nô lệ về mặt tinh thần, tư tưởng còn đáng sợ hơn. Nó làm cho con người ta hoàn toàn tê liệt phản ứng, tiêu tán ý thức đấu 
tranh, an phận, cam chịu. Sự nô lệ về tư tưởng ngày càng ấn con người xuống thấp hơn. Chế độ phong kiến hơn một ngàn năm, chế độ thực dân - phong kiến gần một trăm năm với những tư tưởng, giáo điều về tôn ti trật tự xã hội như quân thần, phụ tử, phu thê, tam tòng tứ đức, quân tử - tiểu nhân... luôn luôn ám ảnh trong đầu óc của những người bị trị, ăn sâu vào nếp nghĩ của họ. Người ta mặc nhiên thừa nhận nó như một chân lí không thể đổi khác. "Họ lo trộm, cướp ban đêm và nhũng trộm cuớp ban ngày. Bất cứ cái gì cũng khiến họ lo, họ sợ. Họ là những người nhẫn nại đến cực độ, luôn luôn nhận mình là con sâu, cái kiến, con giun, con dế, ai muốn dẫm lên cũng được, những kẻ bị bóc lột, đè nén, ức hiếp, đánh chửi đã quá quen rồi, nên hầu như không còn biết phẫn uất gì". Nghiêm trọng hơn, như hiện thực mà Nam Cao phản ánh, người ta lại áp dụng ngay những tư tưởng đó vào việc giải quyết những quan hệ xã hội trong nội bộ giai cấp, tầng lớp mình. Tính ích kỉ cũng từ đây mà ra. Phó mặc, phớt lờ số phận của những người cần có sự cảm thông cũng xuất phát từ tư tưởng an phận, thủ thường. Dân làng Vũ Đại xa lánh Chí Phèo một phần cũng bởi vì họ sợ quyền lực của Bá Kiến. Phân biệt ngôi thứ, khinh miệt những người ở địa vị thấp hơn mình ở cái danh hão cũng từ đây. Vì thế người ta cố công "mua danh". Người ta "có thể cho kẻ khác tát một cái để được lợi một vài hào, nhưng lại rất có thể vứt ra đôi, ba trăm để được người ta gọi là ông phó, những người luôn luôn tính toán nhưng lại tính rất nhầm: họ tiếc không dám giết một con gà cho bố mẹ ăn, nhưng nếu bố mẹ chết đi, lại rất có thể giết đến mấy con bò để làm ma thật lớn...". Cố chấp, không tha thứ cho những người phụ nữ vì lâm vào hoàn cảnh mà phạm lầm lỗi cũng xuất phát từ sự nô lệ này...

Tư tưởng của Nam cao thực sự là một hồi chuông cảnh tỉnh, báo động về thực trạng nhận thức sai lầm, lệch lạc, tiêu cực của một số không nhỏ những người lao khổ. Vấn đề mà nhà văn đặt ra cho đến ngày nay vẫn hết sức có ý nghĩa.

Theo từng bước đường của số phận một số nhân vật thể hiện vấn đề định kiến xã hội, như Đức trong Nưa đêm, cu Lộ trong $T u$ cách mõ có thể thấy rất rõ diễn biến của mối quan hệ giữa cộng đồng và những con người này. Nếu tóm lược diễn biến đó sẽ có một quá trình diễn biến chung nhất: Họ bị định kiến xã hội tấn công - Họ chống lại định kiến nhưng không nổi - Họ bị định kiến quật ngã. Một kết cục không thể khác. Điều này đã khẳng định mãnh lực vô hình của định kiến xã hội. Không đơn giản chỉ là những thói hư, tật xấu, định kiến xã hội thực sự là một nguy cơ, một căn bệnh xã hội vô cùng đáng sợ, cần phải mau chóng loại bỏ nó.
Vấn đề định kiến xã hội bắt nguồn từ cảm quan hiện thực sâu sắc của Nam Cao. Qua cách nhìn nhận của ông, những người bị xã hội coi là những kẻ xấu xa, du côn, tham lam, bầy hầy... đều là những người tội nghiệp, đáng thương. Họ tha hoá, trở thành những người bất hảo hầu như không phải do bản chất của họ, trở thành những người bất hảo hầu như không phải do bản chất của họ, mà do sự xô đẩy của hiện thực cuộc sống. Họ cần được cảm thông, được tha thứ để trở về với cuộc sống.

Phân tích và chỉ ra nguyên nhân, cơ sở xã hội của căn bệnh tư tưởng này, Nam Cao đã chứng minh sáng tỏ quan điểm nhìn nhận, đánh giá con người của mình. Con người luôn luôn chịu sự tác động của hoàn cảnh. Bao kẻ lầm lỗi, xấu xa mà Nam Cao đã khắc hoạ phần lớn là nạn nhân tội nghiệp của hoàn cảnh. "Không một cái tội to tát nào không thể tha thứ. Không một người nào không đáng cho ta thương xót và an ủi" (Sống mòn). Họ - những kẻ lầm đường lạc lối - cần được cộng đồng xã hội tha thứ, che chở, cảm thông. Nhà văn cho rằng những con người cùng một tầng lớp, một giai cấp, cùng một cảnh ngộ nghèo khó cần biết thương yêu, đùm bọc lẫn nhau. Nhân vật Lộc - một trong nhiều số phận, nhiều cuộc đời của Chuyện nguời hàng xóm đã từng thay mặt nhà văn phát biểu tư tưởng ấy. Cậu bé Lộc nghịch ngợm, hiếu động, đến gần cuối truyện đã trở thành một nhà văn. Lộc dám gạt mọi định kiến về quá khứ của một cô Tiền đã từng là gái bán hoa, đề nghị được kết hôn với cô. Anh nói với Tiền: "Ba chúng mình cùng khổ như nhau. Những kẻ khổ sở trên đời nếu không biết thương nhau thì còn đợi ai thương nữa?".

"Những kẻ khổ sở trên đời nếu không biết thương nhau thì còn đợi ai nữa?" - câu hỏi hàm chứa bao đau đớn và thật nhiều hi vọng của nhà văn về một xã hội con người đối xử với nhau bằng lương tri và tình nhân ái.

7. Với tôn chỉ phản ánh hiện thực, nhiều nhà văn hiện thực phê phán cùng thời với Nam Cao như Ngô Tất Tố, Nguyễn Công Hoan...đều có những tác phẩm thể hiện những khía cạnh khác nhau của một xã hội thực dân nửa phong kiến với màu sắc ảm đạm, thê thảm. Tuy nhiên, nếu như phần lớn các nhà văn hiện thực phê phán đi vào phản ánh hiện thực bề mặt thì Nam Cao nghiêng về phản ánh hiện thực ở bề sâu; hơn thế ông còn cố gắng tìm ra nguyên nhân, cắt nghĩa lí giải cũng như tìm giải pháp cho vấn đề hiện thực đó. Vấn đề định kiến xã hội chính là một minh chứng điển hình cho cách phản ánh hiện thực xã hội đó của Nam Cao. Đó cũng chính là câu trả lời vì sao nhà văn Nam Cao đã có một vị trí không thể thiếu trong dòng văn học hiện thực phê phán. 
8. Cho dù cuộc sống xã hội đã đổi thay, nhưng những nếp nghĩ xưa đã ăn sâu trong nhận thức con người, chuyển từ thế hệ này qua thế hệ khác, không dễ một sớm một chiều thay đổi. Cuộc sống càng nhiều bon chen, sự khác biệt giàu nghèo càng rõ nét thì định kiến xã hội càng có đất để sinh sôi. Chính vì thế, có thể nói vấn đề định kiến xã hội, môi trường, những nguyên nhân nảy sinh, cách cắt nghĩa lí giải và một vài giải pháp ban đầu mà Nam Cao thể hiện trong tác phẩm cho đến ngày nay vẫn còn tính thời sự.

\section{TÀI LIỆU THAM KHẢO}

1. Huệ Chi - Phong Lê, Con nguời và cuộc sống trong tác phẩm Nam Cao, Tạp chí Nghiên cứu văn học, số 1 - 1961;
2. Hà Minh Đức (1961), Nam Cao, nhà văn hiện thực xuất sắc, Nxb Văn hoá, Hà Nội;

3. Phong Lê, "Sống mòn" và tâm sụ của Nam Cao, Tạp chí Văn học, số 9 - 1968;

4. Nguyễn Đăng Mạnh (1996), Con đioờng đi vào thế giới nghệ thuật của nhà văn, Nxb Giáo dục, 1996;

5. Trần Đăng Xuyền, Quan điểm nghệ thuật của Nam Cao, Tạp chí Văn nghệ quân đội, số 121 - 1991;

6. Nhiều tác giả (1998), Nam Cao - về tác giả và tác phẩm, Bích Thu tuyển chọn và giới thiệu, Nxb Giáo dục. 